\title{
Choosing an Outlet for Action Research: Publication Patterns in Innovation Journals Magnus Hoppe
}

\author{
'Why not go out on a limb? Isn't that where the fruit is? \\ Frank Scully (1892-1964) \\ Journalist and author
}

\begin{abstract}
With the aim to help innovation researchers choose outlets for articles based on participatory and action research methods, this article describes and discusses publication patterns of action research. A bibliographic study of 33 innovation journals ranked 4, 3, 2, and 1 in the 2018 Academic Journal Guide is complemented by a case study of this journal, the Technology Innovation Management Review, as an example of an established open access journal in the field with a wider scope and target group. From these two studies, we learn that the overall trend is towards more publications of action research articles in a diversity of outlets. Indirectly, the study supports the general view that articles striving towards adding practical relevance to research are becoming more frequent. There is no support for the notion that more renowned and higher-ranked journals would be more hesitant to accept articles with action research methods. The study also notes that there are interesting outlets beside those highly ranked and indexed in more conventional ways. The conclusion reached is that we lack a clear answer to the question of what are the best outlets for those of us who are interested in both innovation and action research. Instead, the study invites us to reflect upon what kind of impact we want to have and then act accordingly.
\end{abstract}

\section{Introduction}

What are the best outlets for those of us who are both interested in innovation and action research? Especially for those of us who would like to combine practical impact with an academic career, this is an important question. Bibliometric rules and arguments from institutional managers often favour established procedures, demanding not just any publications, but publications in high-ranked journals, or "proper journals", as Shani and colleagues (2007) write. As an action researcher, this requirement can be cumbersome given that well-established and high-ranked journals might be hesitant to accept articles based on action research methods, according to MacIntosh and Wilson (2003) and Mathiassen, Chiasson, and Germonprez (2012), but at least "some good journals do sometimes publish action research" as Ahlstrom (2015) phrases it. However, for action researchers, this positive development is quite recent and specific to certain fields (e.g., education and health) and does not encompass technology and innovation, according to Flicker (2014).
What distinguishes action research from other research traditions are an interest to make a direct impact on practical problems, that is to create action, and the involvement of those concerned in problem definitions and knowledge constructions. It is based on democratic ideals, where the interests and demands on questions asked, methods used and results, sought from both researchers and those researched are equally respected (Dewey, 1937; Johansson \& Lindhult, 2008; Lewin, 1946). One-sided scientific control of the research process, including control of analyses and interpretations, will not do, and this approach therefore challenges dominating scientific ideals that rest on upholding the divide. The mutuality of action research is sometimes highlighted through adding the prefix participative or participatory to action research. Action research has slowly been gaining acceptance over the years, and there are now two well-established dedicated journals: Action Research (established in 2003 by SAGE) and the International Journal of Action Research (established in 2005 by Rainer Hampp Verlag). Browsing published titles, one can note that these two journals are dominated by health, education, 


\section{Choosing an Outlet for Action Research: Publication Patterns in Innovation Journals} Magnus Hoppe

and development studies, thus supporting Flicker's (2014) statement above. Technology and innovation are covered, but they are not part of the mainstream.

After researching what has been written on the publishing topic, there is no clear answer available to the initial question regarding the best publication outlets for action researchers. Instead, we are left with quite weak value-laden statements as those above. Answers are incomplete and concluding statements are mostly circumstantial, pointing to the fact that action research articles still do not match the standards of high-ranked journals, and thus are being rejected. Shani and colleagues (2007) suggest that these standards mainly are applied in order to protect the publishers' reputation, where action research has been considered questionable. Exactly what the standards are also varies from institution to institution and person to person (Shani et al., 2007), making it hard for an action researcher to judge the chances of being accepted. Schön (1995) provides us with a possible explanation to this problem, describing action research as scientifically different with an epistemology and standards of its own where practical relevance is part of the scientific rigour and not something that can be disregarded.

On the other hand, new research approaches and mixed methods are making their way into high-ranked journals, and among those, some rely on action research. The reason for this development, according to Rau, Goggins, and Fahy (2018), is the current societal demand for research to have social impact, not only scholarly impact. This demand also paves the way for publications in open access journals. When introduced, open access first appeared as another outlet option for researchers. Now, there are voices turning the optional outlet into the preferred outlet, even making it mandatory in certain circumstances. An example of this demand is an agreement from September 2018, when eleven European countries approved "Plan S", which requires that, "from 2020, scientific publications that result from research funded by public grants must be published in compliant Open Access journals or platforms" (cOAlition S, 2018). This development should come as no surprise, as there is general movement in society towards open approaches. Since the turn of the millennium, open approaches, where different actors get together in order to create change through active participation in knowledge building, culminating in some kind of action, appear to becoming the new norms that drive society (cf. Chesbrough, 2003). Action research is thus well in tune with the overall societal development, especially when the prefix participatory/participative is added to different knowledge processes.

Summing up, "open" as the new normal, the establishment of open access journals, and now public demands for open publishing, are growing concerns for both publishers and researchers. The former sees their traditional business models crumble, and several now offer open access for a fee. The latter are instead given more approved choices when looking for the best outlets. Even though there are many predatory journals luring researchers into low-quality outlets with mysterious payment schemes, there are also well-established open access journals that uphold scientific rigour through peer review, for example, and thus represent valid options for serious researchers. In the midst of this development, the initial question remains, and the purpose of this article has been specified to describe and discuss action research publication patterns in innovation journals.

In order to meet this purpose, a limited bibliographic review of 33 journals was undertaken. The bibliographic study was then complemented with a case study of the TIM Review in order to build an example of a contemporary journal with an agenda for bridging the knowledge gap between theory and practice (quite in line with the action research agenda of many researchers). In the remainder of this article, the results of both studies are described and analyzed with the aim of helping researchers choose outlets for articles based on participatory and action research methods.

\section{Bibliographic Study}

The bibliographic study consists of a limited review of all 33 journals listed in the innovation category of the Chartered Association of Business Schools' 2018 Academic Journal Guide (AJG; charteredabs.org/academic-journalguide-2018/). This study especially addresses questions of rank in relation to frequency of published action articles over the years.

The choice of the AJG as a base for the selection is explained by its well-established use in business schools. It is also quite stable. Compared to the 2015 AJG, the 2018 version used here displays just one change in ranking, which is that the journal Research Policy has moved up from 4 (top journals) to $4^{*}$ (journals of distinction). The 2018 edition also encompasses four new journals, all ranked 1, moving the index from a total of 29 journals to 33. The index is dominated by lower-ranked journals, as can be viewed in Figure 1 . 


\section{Choosing an Outlet for Action Research: Publication Patterns in Innovation Journals}

\section{Magnus Hoppe}

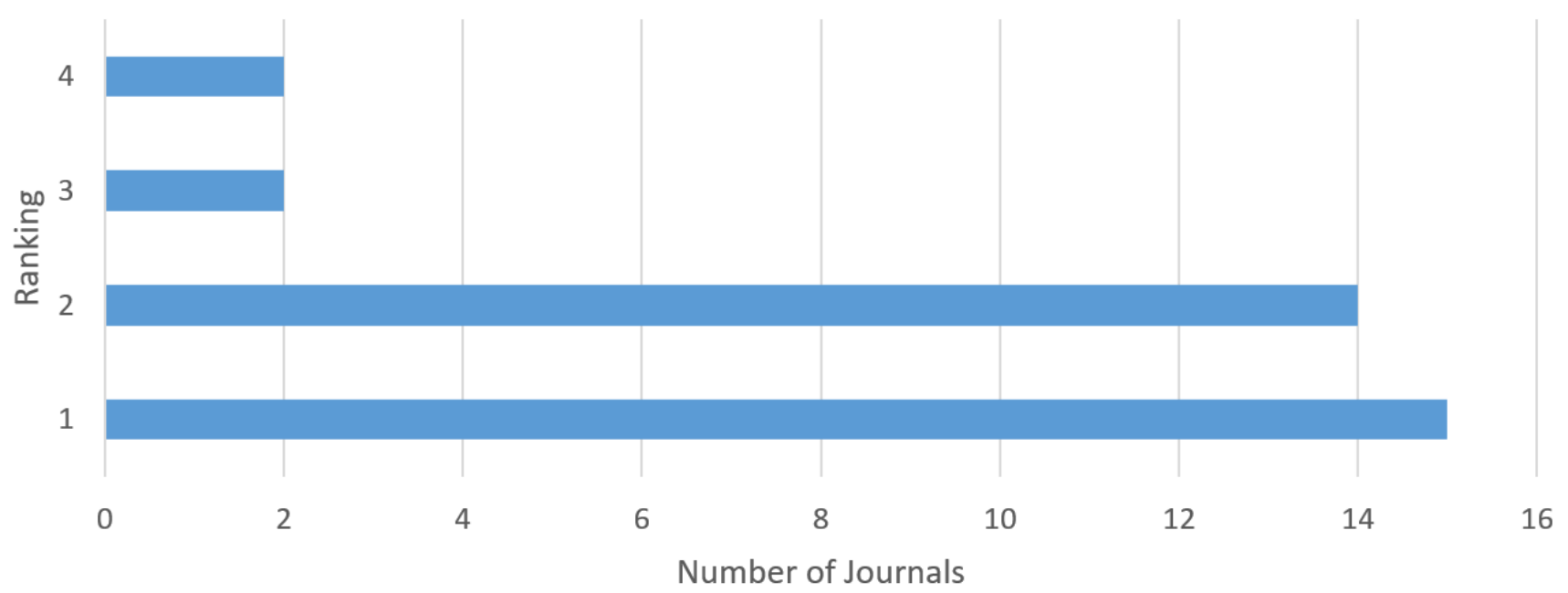

Figure 1. Number of innovation journals by ranking in the 2018 AJG

The ranking is described as follows in the AJG:

Rank $4^{*}$ Grade 4 journals that are recognized worldwide as exemplars of excellence

Rank 4 Journals that publish the most original and best-executed research

Rank 3 Journals that publish original and wellexecuted research papers and are highly regarded

Rank 2 Journals that publish original research of an acceptable standard

Rank 1 Journals that, in general, publish research of a recognized, but more modest standard in their field

\section{Data collection}

The bibliographic study is divided into two parts. The first part includes 18 journals ranked 4,3 , and 2, accessed through searches using academic library access and individual searches through the homepage of each journal. The second part includes 15 journals ranked 1, researched using Google Scholar. The different parts are presented separately. By doing this division, the influence of less established and novel journals will interfere less with the overall trend of more established journals.

The search terms used for the study are "action research", "participatory research", "participative research", "participatory action research", and "participative action research". In the analysis, the last four terms are grouped in pairs as they are judged to be synonyms, as follows: "participatory/participative research" and "participatory/participative action research".

The study encompasses the years from 1968 (the first mentioning of action research) to 2018, although most journals were not founded at the time of the first mentioning. The total tally for each year can thus not be compared straight off. The year 2018 is also included, although with incomplete records as the study was conducted in December of that year.

\section{Analytical approach}

For an article to qualify, it must exactly match one of the five search terms, where it is important to observe that "participatory/participative action research" also will show up in the more general search for "action research". Accordingly, the compilation does not claim to give the exact numbers of articles, instead it gives an overview of how many articles mention the five interrelated search terms. In this way, "participatory/participative action research" shall be regarded as a subcategory of "action research" that was extracted from the total number in the presentation, where the combined number gives us a total for all articles mentioning any form of "action research".

Furthermore, it should be noted that the study does not consider if there is just a brief mentioning of a term in passing or if it was a central term reoccurring throughout an article. The study does thus not reveal how many specifically claimed participatory and action research articles that are actually published by the journals. The mentioning of the terms should instead be seen as proxies for a publication pattern that would 


\section{Choosing an Outlet for Action Research: Publication Patterns in Innovation Journals} Magnus Hoppe

only be possible to assess through a qualitative study. This, in turn, would be dependent on full access to all articles in all journals, which we do not have at present. The results are thus more indications through proxies than complete or correct numbers.

As discussed by Reason and Bradbury (2008), there are many different names for action research, which means that a choice of other search phrases than the five mentioned would give different results. The choice of these specific five terms are, however, justified as follows. Our presumption is that "action research" will return articles expressly addressing expressed methodological choices, whereas "participatory/participative research" will return articles especially addressing the relationship between the researcher and the researched. The combined term "participatory/participative action research" will consequently return articles addressing both these angles. All this assumes that the authors have reflected on the terms used, which they should have given that information about methodological choices usually is prioritized in research articles.

Reflecting on these matters in the outset, we also hypothesized that the terms "participatory" and "participative" ought to be more commonly used as methodological descriptors in recent articles due to the popularization of open approaches and a movement toward dismantling borders between the researchers and the researched, as described by Rau and colleagues (2018).

\section{Complementary Case Study: The TIM Review}

The bibliographic study is built on an index constructed by an expert group, favouring a conventional way of ranking innovation journals that need to qualify to be included. However, newer journals emphasizing broader goals (including quality) are easily neglected and may remain unranked. As discussed in the introduction, an array of new journals has been launched outside the conventions that make the AJG possible. Still, one might wonder how the publishing patterns of a new type of journal compare to that of those in a traditional index. For comparative reasons, a singular case study of the journal Technology Innovation Management Review (TIM Review; timreview.ca) was conducted. The choice of TIM Review came naturally as it is the outlet for this article (as part of a pair of special issues dedicated to action research), but it also represents a well-established open access journal with an aim of spreading know- ledge across disciplines and to both scholars and practitioners. It should also be more interesting to the readers to have data on the very journal they are reading, instead of some other possibly just as relevant journal. In other words, including TIM Review invites the readers to directly reflect upon claims made in this article with their first-hand experiences of the journal.

For this complementary study, data was collected using Google Scholar's advanced search, but following the same pattern as for the bibliographic study. The analytical approach was also the same as for the bibliographic study but was complemented with a few qualitative additions made possible through open access to both articles and the Editor-in-Chief (quite in line with growing ideas of relevance and the epistemology that builds action research, one might add).

\section{Results}

The result section is divided into two sections. First, we present the findings and analysis of the bibliographic study's two parts: journals ranked 4, 3, and 2 and then journals ranked 1 . Second, we do a similar analysis for the TIM Review. This is followed by an analysis and a discussion that more specifically address publication patterns and the questions guiding this article.

\section{Journals ranked 4, 3, and 2}

The first part of the bibliographic study (journals ranked 4, 3, and 2) includes a total of 423 articles going back to the publication of the first action research article in 1968. Of these 423 articles, 319 contain the general term action research, 32 articles contain the more specific term participatory/participative action research, and 76 contain the term participatory/participative research. For the period between 2000 and 2018, these different categories amount to 228, 26, and 67 articles, respectively.

As visible in Figure 2, all researched terms show an increase over the studied period. For action research, this is continuous growth, whereas the other terms are more stochastically mentioned but reoccurring from about the year 2000. From 2000 onwards, there are about 13-14 action research and 3-4 participatory/participative research articles published each year within the innovation category of the AJG journals ranked 4, 3, and 2. Of the 13-14 action research articles published each year, typically only 1 or 2 use the more specific term participatory/participative action research. 


\title{
Choosing an Outlet for Action Research: Publication Patterns in Innovation Journals
}

\author{
Magnus Hoppe
}

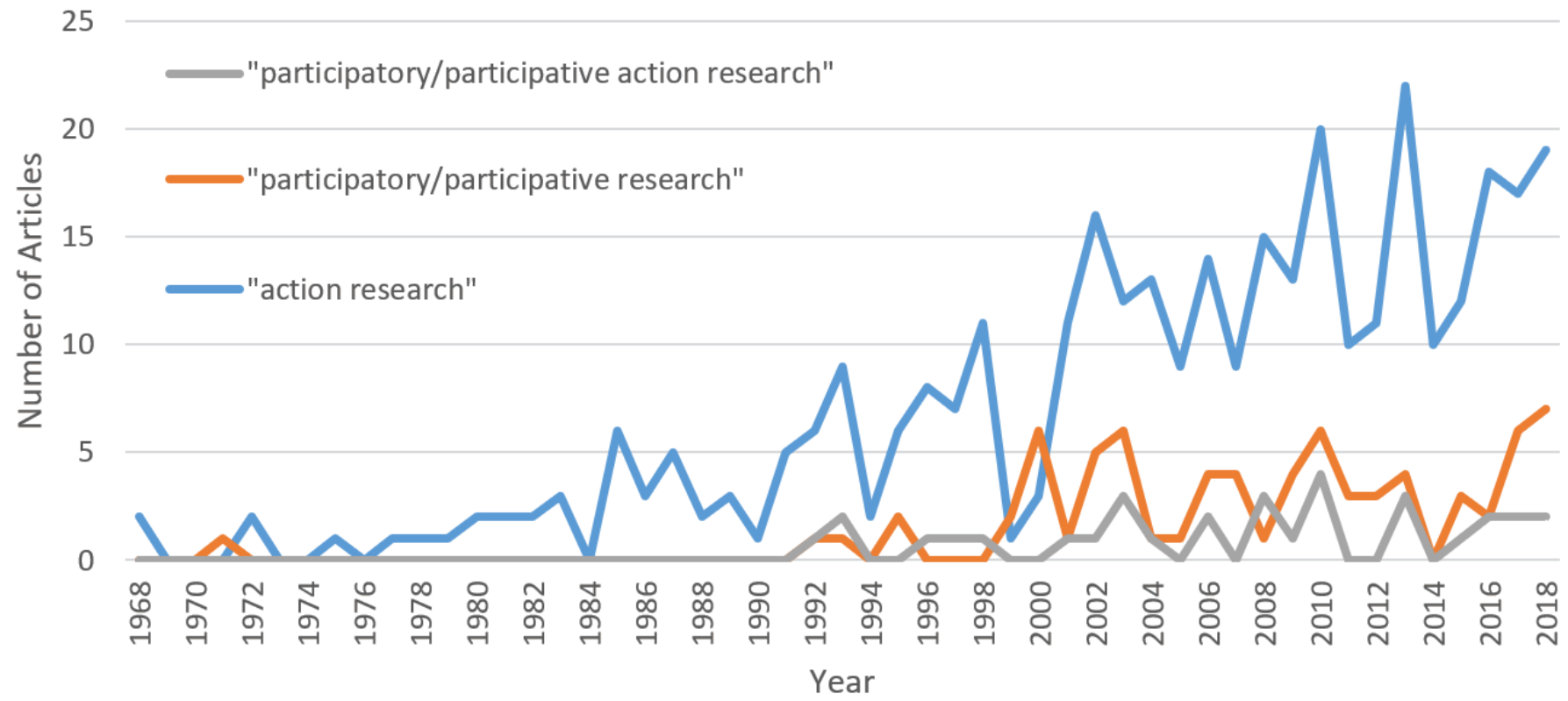

Figure 2. Total number of published articles in journals ranked 4, 3, and 2 included in the AJG mentioning action research, participatory/participative research, and participatory/participative action research between 1968 and 2018

There is no support for the notion that any of the examined terms have been used relatively more frequently over this 18-year period; instead, the terminology pattern seems quite stable from the year 2000 onwards. But, if we instead compare the periods before and after the year 2000, participatory/participative research has become more frequent, moving from 1 article out of 11 in the period before the new millennium to 1 article out of 5 in the period that follows.

A total of 311 articles were published since the year 2000, leaving a total of 106 articles published up until 1999. Hence, about three-quarters of all articles were published after the year 2000. The oldest articles mentioning action research are from 1968 (both of them in Research Technology Management: International Journal of Research Management) followed by one article from 1972 (in Research Policy). Complementary to this, there is an article in Social Studies of Science from 1971 that mentions participatory/participative research. Thus, there are articles published $45-50$ years ago that mentioned the central concepts of this study, although it is not until the 1990s that we see recurrent publication of the terms participatory/participative research and participatory/participative action research.

From the start in 1968, there was, on average, an article mentioning action research every second year until the 1980s where publications reach two articles a year. In the 1990s, it averaged a bit over six articles a year. From the year 2000, the relative development is slower, moving from about 10 articles a year at the beginning of the millennium to closing in on 20 the last three years, ending in 2018.

Journals that stand out with a long and relative extensive publication record for articles mentioning action research before the year 2000 are Technovation (27), $R \& D$ Management (11), Research Policy (10), and Creativity and Innovation Management (10). When it comes to the total number of published articles with the term action research since 1968, at the top of the list is Technovation (66), closely followed by Research Policy (63), and then Creativity and Innovation Management (47), and $R \& D$ Management (36). Of these four, it is only Creativity and Innovation Management that is ranked 2. The other three are ranked 3 or 4 . The remaining journal in the AJG ranked 4, the Journal of Product Innovation Management, displays a total of 15 action research articles, but all of them are from 2003 or later (even though the journal was instigated in 1984), and the journal is now averaging one action research article a year. The findings indicate a more open stance towards action research in recent years for this journal.

The latter part of the review, from the year 2000 to 2018, is summarized in Figure 3, where the journals are listed in the order of the AJG. The numbers at the top of the figure indicate the journals' 2018 rankings. 


\title{
Choosing an Outlet for Action Research: Publication Patterns in Innovation Journals
}

\author{
Magnus Hoppe
}

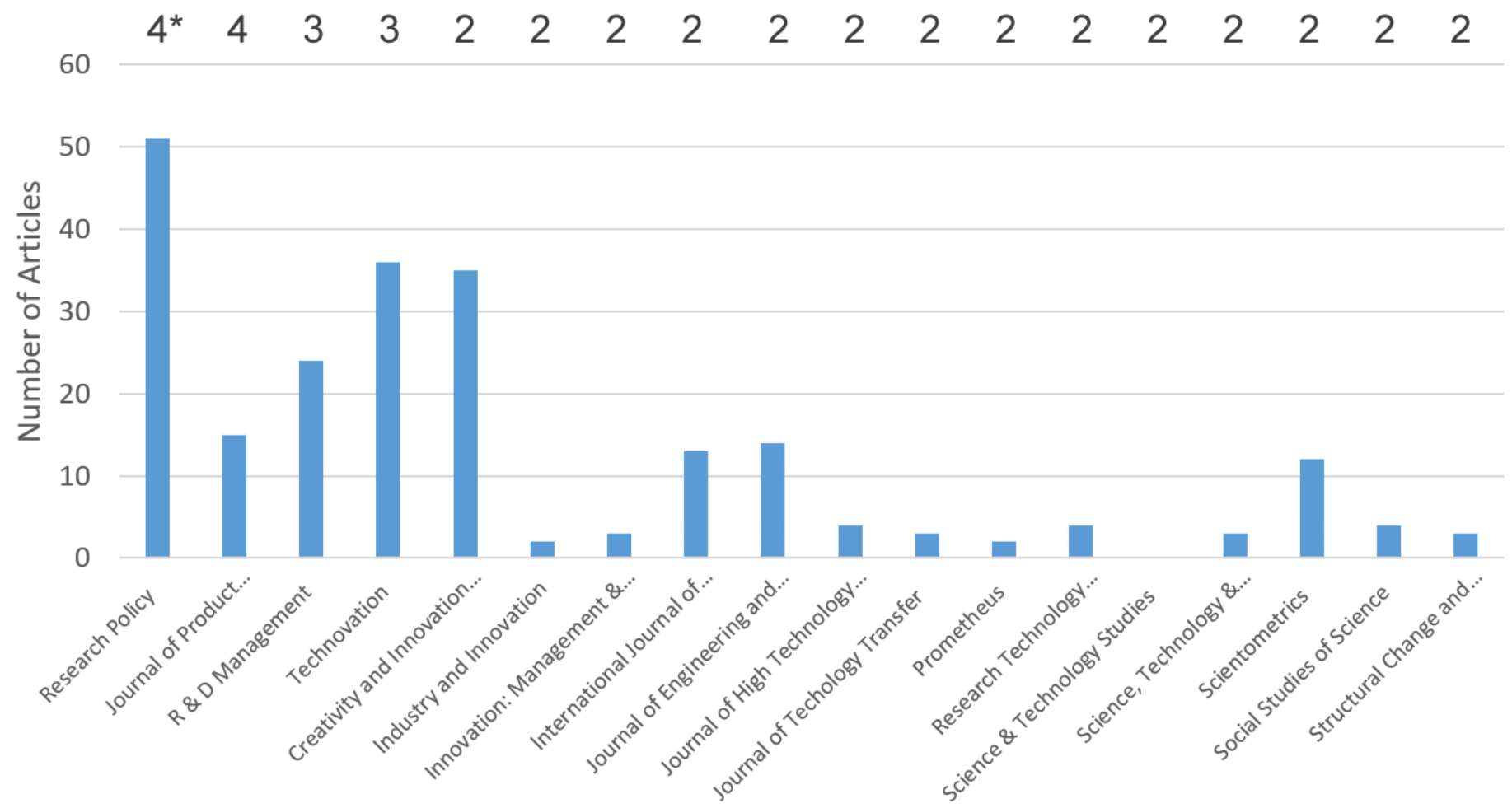

Figure 3. Number of articles mentioning action research published between 2000 and 2018 in individual innovation journals ranked 4,3 , or 2 in the AJG

Judging by Figure 3, the four journals ranked 4 and 3 appear to be the main outlets for action research articles, followed by Creativity and Innovation Management (35), the Journal of Engineering and Technology Management (14), the International Journal of Innovation Management (13), and Scientometrics (12).

Turning to participatory/participative research, most journals do occasionally publish articles using these terms, but one journal stands out. Science, Technology \& Human Values totals 18 articles since the year 2000, giving us a neat average of one article a year. Noticeably, there are no articles published in this journal before the year 2000 that mention participatory/participative research. Comparatively, when it comes to mentioning action research, there are eight articles in this journal before the year 2000 and nine articles after 2000, giving a total of 17. This finding indicates that, today, participatory/participative research articles are more likely to pass the review process of this journal than articles with action research, a tendency that has been pronounced since the year 2000. The journal Social Studies of Science has a similar but less distinct publication pattern, slightly favouring participatory/participative research over action research. Among the higher-ranked journ- als, Research Policy and Technovation (both from Elsevier) stand out as they have published articles with participatory/participative research since the early 1990s with a total of 16 articles for Research Policy and 13 articles for Technovation. These totals are quite high compared to the three articles in the Journal of Product Innovation Management (rank 4) and the one article in $R \& D$ Management (rank 3). Noteworthy, Research Policy has 5 recent publications, dating from 2017 and 2018.

Even though the numbers are generally not strong, there are a few interesting publication tendencies. For instance, Technovation has a long record of publishing articles mentioning action research, peaking between 2003 and 2006 with an average of four articles per year, but there is a decline in more recent years. Since 2014, it has published 1-2 articles a year. The other well-established journal with a higher track record compared to the others, Research Policy, does not have the same trajectory. Instead, is it quite stable with 3-4 articles a year. However, although 2018 was not complete at the time of the data collection for this study, a post hoc expansion of the search to include the full year revealed that $R e$ search Policy published six action research articles in 2018, thereby matching its 2010 record. With another 


\section{Choosing an Outlet for Action Research: Publication Patterns in Innovation Journals}

Magnus Hoppe

four open access articles published up until the July 2019 issue, Research Policy thus may be closing in on a new record.

Among the journals ranked 2, both the International Journal of Innovation Management and the Journal of Engineering and Technology Management are quite stable, with 1-2 articles mentioning action research each year. Comparatively, Scientometrics has a divergent publishing pattern. Going back to the period before the year 2000, it published an article mentioning action research every 2-3 years, but from 2000 until 2014 it published none. In 2015, a change came; since then, it has published three articles a year on average.

Finally, the results also show that some innovation journals do not publish much at all in any of the categories.

\section{Journals ranked 1}

The second part of the bibliographic study concerns journals ranked 1 in the AJG. The publication patterns of these journals in the rank 1 category are harder to assess, as many journals of these journals are quite new. There is a total of 149 articles mentioning "action research" for this group, where all were published between 2000 and 2018, save for one published in 1998 by the European Journal of Innovation Management, clearly indicating that this group is dominated by more novel journals. Thus, the unsettled character of this category of journals ranked 1 prevents us from being more specific in terms of yearly patterns, etc.

As can be expected, journals with a longer publication record within this category also display more articles mentioning "action research". Figure 4 gives an overview of the number of action research articles in each journal. At first glance, the pattern is similar to that of journals ranked 2 visible in Figure 3. Due to differences in the search methods and data available for the two categories, it would be hazardous to claim any major variance.

Journals ranked 1 also publish articles mentioning participatory/participative research at about the same rate as journals ranked 4,3 , or 2 , with a total of 40 articles for this period counting all journals. There is about one article mentioning participatory/participative research for every four articles mentioning action research.

Journals that stand out are the four with most articles mentioning action research: the International Journal of Innovation and Technology Management (27), the International Journal of Entrepreneurship and Innovation Management (24), the European Journal of Innovation Management (18), and the International Journal of

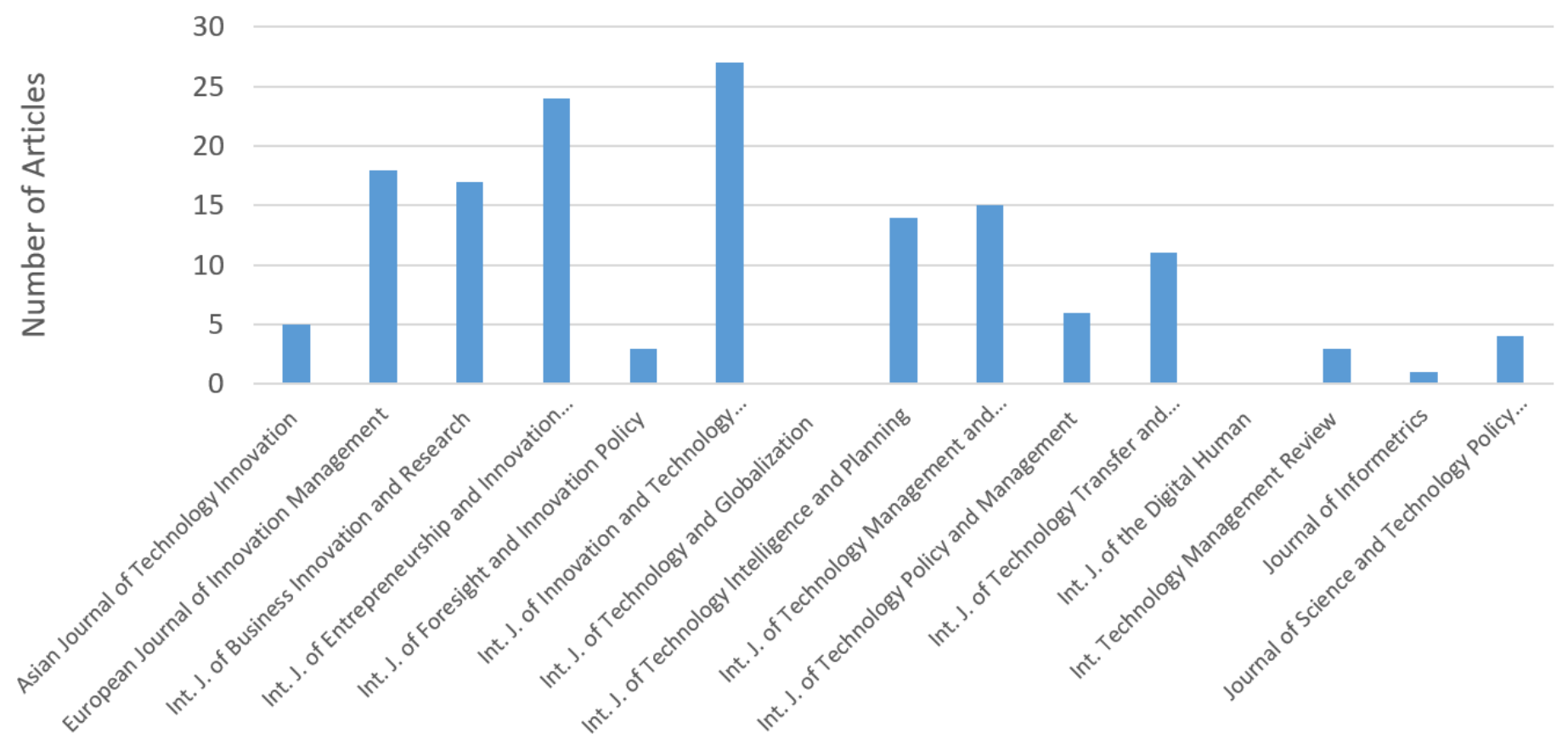

Figure 4. Number of articles mentioning action research published between 2000 and 2018 in individual innovation journals ranked 1 in the AJG 


\section{Choosing an Outlet for Action Research: Publication Patterns in Innovation Journals} Magnus Hoppe

Business Innovation and Research (17). All these four journals also publish quite a few articles (a total of 21) containing the terms "participatory/participative action research" and "participatory/participative research", indicating at least a general interest in these approaches.

\section{The TIM Review}

Since its first issue in July 2007, the Technology Innovation Management Review (TIM Review) has turned out a total of 30 articles mentioning participatory and action research. The first appear in 2012 with a surge of articles from 2016, as shown in Figure 5. Starting in 2016, it has averaged eight articles a year (out of a total output of approximately 60 articles a year). With two special issues on action research to be published in 2019, this trend is likely to hold or increase.

Looking closer at the articles published, most of them (25) are restricted to the term "action research". Three articles use "participatory research" and two "participatory action research" (none use "participative"). All of these five were published from the surge in 2016 and onwards, thus also giving some support to a growing interest in participatory/participative research.

Notably, 10 of the 25 action research articles in the TIM Review report on research conducted through living labs. The journal's first action research article (Seppä, 2012) also addressed living labs, and the TIM Review turned out eight special issues on this theme between 2012 and 2018, indirectly boosting the numbers of recent action research articles. In a recent analysis of articles about living labs published in the journal, Westerlund, Leminen, and Rajahonka (2018) conclude that living lab articles in the TIM Review have moved from descriptions of the phenomena towards the design and management of living labs. In this way, turning attention to process issues, action research has become more relevant as a topic for the articles. This is especially noticeable in an article by Logghe and Schuurman (2017) with the title "Action research as a framework to evaluate the operations of a living lab". Also, in the special issue on living labs published in December 2018, two out of five articles mention action research and participatory research. The increase of articles mentioning action research articles can at least in part be said to be dependent on the journals' publication of living lab articles. Nonetheless, articles on living labs represent the minority of TIM Review articles that include the term action research, meaning that the trend of an increasing number of action research articles in the TIM Review goes well beyond the topic of living labs.

\section{Analysis}

The findings from the studies presented here add nuance to earlier claims made in the introductory review. Judging by the figures from the bibliographic study, there is no positive support for the idea that well-established and high-ranked journals would be more hesitant to accept articles mentioning action research compared to lower-ranked journals in the field of innovation, as expressed by MacIntosh and Wilson (2003) and Mathiassen and colleagues (2012). On the contrary, higher-ranked journals, as can be expected, have a longer publication record and have also published articles mentioning action research since well back into the 20th century. The study also indicates that highranked journals no only publish action research but do so without the negative connotation noticeable in the

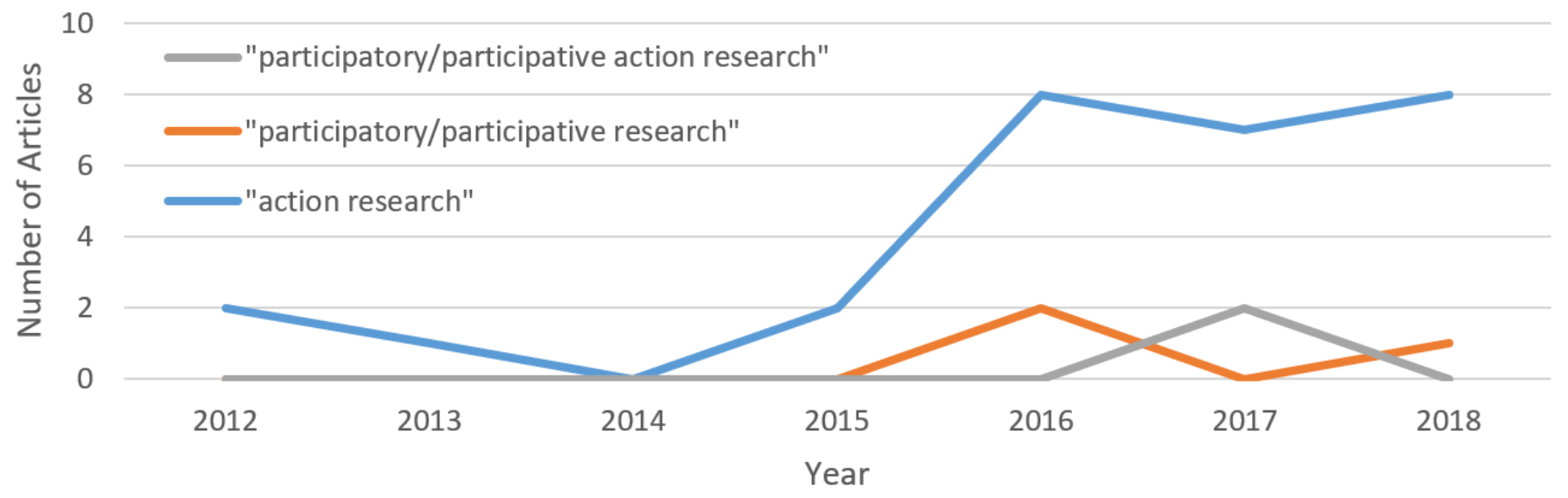

Figure 5. Number of articles mentioning participatory and action research terms in the TIM Review 


\section{Choosing an Outlet for Action Research: Publication Patterns in Innovation Journals} Magnus Hoppe

article by Ahlstrom (2015). The highest-ranked journal, Research Policy, is also the journal that has published most articles containing action research since the year 2000. Noticeably, this journal is also ranked as a journal of distinction in the 2018 AJG, where the journal's relatively frequent publications of articles mentioning action research did not hinder it from moving upwards in the ranking. Adding to this, more recently launched and lower-ranked innovation journals do not, compared to high-ranked journals, especially favour articles mentioning action research, according to the findings of this study. There is also a positive trend for more articles mentioning action research each year in the journals of the AJG, indicating weakening support for earlier claims that action research would be hard to publish in conventional journals.

If we instead go to participatory/participative research, the lower-ranked Science, Technology \& Human Values and Social Studies of Science (both ranked 2), together with the higher-ranked Technovation (ranked 3), published relatively more articles compared to other journals in the AJG. There is no clear reason for this, except that they all clearly state that they are interdisciplinary or multidisciplinary, with aims to publish research that scrutinizes innovation and current societal development and how it affects both research and human values. Engagement and border-breaking aspects should thus interest the editorial boards and possibly favour publication of participatory/participative research. On the other hand, other journals within the AJG display similar statements, weakening this possible explanation.

Turning to the complementary study, the TIM Review supplies us with an example of a relatively new open access journal with the goal of both serving and reaching out beyond the scholarly sphere. Since 2012, it has published publish action research articles, and increasingly so. Complementary information from the Editor-inChief explains this trend, in part, based on the increasing attention paid to action research at conference events put on by the International Society for Professional Innovation Management (ISPIM; ispim-innovation.com), which has frequently partnered with the journal on special issues. It is his impression that action research has become a growing topic of interest at ISPIM events, and this increased awareness has possibly increased his propensity to encourage submissions of articles based on action research. However, the increase of action research articles in the TIM Review is not something unique. Although it is not included in the $2018 \mathrm{AJG}$, it follows the overall trend for the journals ranked 4,3 , and 2 in the AJG, where the total output is close to 20 articles a year since 2016. But, at that point, the similarities end. Since then, the TIM Review has published eight action research articles a year, where the average is just about one article a year for the journals in the AJG. Interestingly, it is the most renowned conventional journal, Research Policy, that this last year, 2018, has almost come to match the TIM Review's total.

In the result section, the publication patterns of a few journals were noted to change suddenly. For example, Scientometrics displayed a surge in 2015 after a long period with no action research publications at all, whereas the TIM Review has an even more dramatic increase in articles from 2016. Possible reasons behind these changes are adjustments in practiced institutional and personal standards, as discussed by Shani and colleagues (2007), for example, through the substitution of editors. Although this is not the case for the TIM Review, we cannot rule out that this explanation holds for other journals. Another possible reason behind temporal surges is the publication of special issues. For instance, MacIntosh and Wilson (2003) mention that Human Relations (not part of this survey) had a special issue on action research in 1993 that encompassed 12 articles, thus obscuring an underlying trend. But, special issues would only boost the numbers for specific years. As all parts of the study show that more and more articles are being published each year, it indicates that institutional or personal standards are becoming more positive towards action research. It is also possible that these standards are moving with the whole innovation field and that publishing patterns just follow. If an increasing number of research projects are conducted using action research methods, it should become visible in the relative number of published articles.

As the general publishing development within the AJG is quite stable over the years, there is no real support for claiming that ideas of more open development processes should have had any significant influence on the methods used and described in innovation articles, except for a more pronounced use of participatory/participative research in the reviewed journals from the year 2000 and onwards, and in the TIM Review from 2016. There is thus some support for our hypothesis that the terms "participative" and "participatory", due to the popularization of open approaches and efforts to dismantle borders between the researchers and the researched, ought to be more commonly used as methodological descriptors in recent articles. 


\section{Choosing an Outlet for Action Research: Publication Patterns in Innovation Journals} Magnus Hoppe

Finally, there are a few journals that do not appear to have published anything at all mentioning "action research", which is worth reflection. It might be due to the search terms used and the journals' indexation in Google Scholar, for example. However, if we assume that these numbers are correct, a possible explanation might be that these journals do publish articles with a research design similar to action research, but they use another vocabulary to describe it (Reason \& Bradbury, 2008). Still, the term action research seems to be excluded from a few innovation journals.

\section{Discussion}

The results presented here imply that all journals, regardless of rank, are about as keen or hesitant to publish action research articles. Contrary to expectations, the high-ranked journals seem to be even more positive towards action research than the low-ranked ones. But this might be a generalization too far. Instead, it is the individual differences between journals that are most prominent in this study.

The journals present in the current study, and especially those highly ranked ones, have a long publishing record and are predominantly built on more conventional publishing standards within a specified field. New publishing channels do not have to obey to these kinds of limitations. Hence, it is likely that the most interesting publishing trends, especially for interdisciplinary or multidisciplinary action researchers, will appear outside the publishing of conventional and indexed journals. New journals and publishing models, including open access publishing, in this perspective, are both a complement and an alternative to conventional outlets. But, there is no clear answer to the initial question of what the best outlets are for those of us who are interested in both innovation and action research. Instead, the study invites us to reflect upon what kind of impact we want to have and then chose outlets accordingly. What the study also indicates is that there are interesting outlets beside those ranked and indexed in more conventional ways. In some respects, action researchers interested in innovation might have more publication options than those with more bounded ideas of scope and objectives, and that is solace for battered souls pressed by academic managers and demands for more citations.

The number of published action research articles has successively increased over the years, and close to 20 articles are now published yearly in innovation journals ranked 4, 3, and 2 in the AJG. In particular, we see an increased interest in participatory/participative research since the year 2000 - a trend also visible in the articles published in the TIM Review, but then for a more recent period. The study thus indicates that action research methods at least are mentioned more frequently in recent research articles on innovation. Indirectly, the results also suggest that articles striving towards adding practical relevance to research are becoming more frequent. A word of caution though: these claims are built on absolute numbers and not relative numbers. We cannot rule out that the positive trend is part of an overall increase in academic output in the indexed journals.

From the bibliographic study, we also conclude that there is no support for the notion that more renowned and highly ranked journals would be more hesitant to accept articles with action research methods. On the contrary, highly ranked journals (ranked 4 and 3 in the study) seem to be even better conventional outlets for action research compared to lower ranked journals (ranked 2 and 1). A researcher that strives for conventional impact in the innovation field should therefore not hesitate to submit to the most prestigious and highly ranked journals in the field but will do well in looking into the publishing history of each considered journal.

The most interesting publication pattern noticed through the bibliographic study might be that there is not much in the way of clear patterns at all. This is due to the fact that the total score of mentions of action research is quite limited within this finite sample. Each published article counts as much and has great effect on the total (at present, one new article increases the number of total publications by 5 percent a year for journals ranked 4,3 , and 2), meaning we should be careful not to "make a hen out of a feather", as we say in Sweden. However, the overall publishing trend is positive for action researchers in terms of the increasing total number of articles related to action research being published each year.

The case study of the TIM Review does not so much challenge the bibliographic study but complements it with an example of an established open access journal that seeks to reach readers from both academia and surrounding society. The TIM Review appears not just to follow the general trend of increasing interest in action research but exceeds it with a margin. The surge in action research publications in TIM Review since 2016 is interesting to note for researchers but also practitioners interested in innovation and action research. In total numbers, there are more recent articles addressing action research in this outlet each year than any of the 


\section{Choosing an Outlet for Action Research: Publication Patterns in Innovation Journals} Magnus Hoppe

bibliographic study's journals. Still, as the TIM Review is just an example chosen for convenience and for the interest of its readers, there might be other journals that are even more devoted to action research and participatory methods. It means that both innovation scholars and practitioners should view this journal, and possibly also any other journals with a broader target group as well as those with an open access model, which helps reach a non-academic audience. as not just a viable outlet but also as most relevant when looking for current knowledge and inspiring examples for how to approach both practical and theoretical problems addressed through action research.

\section{Conclusion}

The openness of new research processes as well as in publishing practices might successively change the way we judge, rank, and relate to journals and articles in the future. But we are not fully there, yet. The ranking of the AJG builds on conventional ways of dividing research into specific fields and give good numbers to those journals who have been able to attract attention from a specific audience over time. This has not changed. These journals still count and are important but mainly to those working within academia's traditional paradigm with respect to publications. Open access is sometimes offered by these journals, but only for those privileged with funds for this. This situation does not square well with the democratic ideals, inherited in the traditions of action research and participatory action research, and many researchers might still be standing before a difficult choice between intended academic or societal impact. Even though open access might be offered as a choice when aiming for a highranked journal, it is possibly not enough to get the desired societal impact. A good thing about being an action researcher, however, is that one makes this choice within a context where academic and societal impact are both desirable rather than strange or conflicting.

Reflecting on this choice, some recommendations can be given. On the one hand, researchers should check the fit of their article with the publication record and the publication policy of the desired outlet. A longer and richer publication record will also provide a better choice of internal references to include in an article before submission. On the other hand, if the journal's publication record in the field is minimal but there are interesting statements in the journal's publication policy, it may worth considering contacting the editor with a "sales pitch" for opening up a new stream of interesting articles to fulfill those statements. Building on the popularity of open approaches in innovation might be a complementary argumentative path to pursue.

Facilitating the choice of outlets is the trend towards openness and societal impact - these forces work against obsolete divisions in society between researchers and those researched. There is an increasing number of journals, but also articles as this study reveals, recognizing this. For all of you who feel you do not belong to the traditional "inside of academia" perspective, the study indicates that you (through a rising interest in action research) are increasingly defined as being on the inside of ongoing knowledge constructions, and you have a stake in how we best join together to achieve desired outcomes.

Finally, what we have not assessed in this study, is a more in-depth analysis of the quality, content, disposition, and scope of identified articles. There is thus a need for a complementary qualitative study that addresses other types of publication patterns in the content of the articles covered in this study.

\section{About the Author}

Magnus Hoppe is an Associate Professor at the School of Economics, Society and Engineering at Mälardalen University, Sweden. At the university, he is member of the Faculty Board, and leads processes for collaborative research in sustainable development. Magnus holds a $\mathrm{PhD}$ in Business Administration from Åbo Akademi University in Finland, where he presented his thesis on organized intelligence work in modern organizations. His current research concerns both private and public organizations and spans intelligence, entrepreneurship, and innovation. A special research interest lies in questioning dominating perspectives that bind our understanding of specific topics, and he now works to establish new ways of talking and thinking about innovation. His aim is to help organizations build new insights that will enhance their ideation processes and strategy building and, thereby, improve their innovative capabilities. 


\section{Choosing an Outlet for Action Research: Publication Patterns in Innovation Journals}

\section{Magnus Hoppe}

\section{References}

Ahlstrom, D. 2015. Successful Publishing in Academic and Scientific Journals: Framing and Organizing the Scholarly Paper. International Journal of Higher Education Management, 2(1): $106-120$.

Chesbrough, H. W. 2003. The Logic of Open Innovation: Managing Intellectual Property. California Management Review, 45(3): 33-58. https://www.jstor.org/stable/i40051903

cOAlition S. 2018. What is cOAlition S? Plan S: Making Full and Immediate Open Access a Reality. Accessed April 1, 2019: https://www.coalition-s.org/about/

Dewey, J. 1937. Education and Social Change. Bulletin of the American Association of University Professors (1915-1955), 23(6): 472-474. https://doi.org/10.2307/40219908

Flicker, S. 2014. Disseminating Action Research. In D. Coghlan \& M. Brydon-Miller (Eds.), The SAGE Encyclopedia of Action Research: 276-280. London: SAGE.

Johansson, A. W., \& Lindhult, E. 2008. Emancipation or Workability? Critical versus Pragmatic Scientific Orientation in Action Research. Action Research, 6(1): 95-115. https://doi.org/10.1177/1476750307083713

Lewin, K. 1946. Action Research and Minority Problems. Journal of Social Issues, 2(4): 34-46. https://doi.org/10.1111/j.1540-4560.1946.tb02295.x

Logghe, S., \& Schuurman, D. 2017. Action Research as a Framework to Evaluate the Operations of a Living Lab. Technology Innovation Management Review, 7(2): 35-41.

https://doi.org/10.22215/timreview/1056

MacIntosh, R., \& Wilson, F. 2003. Publishing Action Research. Paper presented at the 19th EGOS Colloquium, Copenhagen.

Mathiassen, L., Chiasson, M., \& Germonprez, M. 2012. Style Composition in Action Research Publication. MIS Quarterly, 36(2): 347-363.

Rau, H., Goggins, G., \& Fahy, F. 2018. From Invisibility to Impact: Recognising the Scientific and Societal Relevance of Interdisciplinary Sustainability Research. Research Policy, 47(1): 266-276.

https://doi.org/10.1016/j.respol.2017.11.005

Reason, P., \& Bradbury, H. 2008. Handbook of Action Research: Participative Inquiry and Practice. London: SAGE.

Schön, D. A. 1995. Knowing-in-Action: The New Scholarship Requires a New Epistemology. Change: The Magazine of Higher Learning, 27(6): $27-34$.

https://doi.org/10.1080/00091383.1995.10544673

Seppä, M. 2012. From Business Administration to Business Creation: The Case of the Kalevala Global Business Creation School. Technology Innovation Management Review, 2(6): 6-11. https://doi.org/10.22215/timreview/562

Shani, A. B., Mohrman, S. A., Pasmore, W. A., Stymne, B., \& Adler, N. 2007. Handbook of Collaborative Management Research. London: SAGE Publications.

Westerlund, M., Leminen, S., \& Rajahonka, M. 2018. A Topic Modelling Analysis of Living Labs Research. Technology Innovation Management Review, 8(7): 40-51.

https://doi.org/10.22215/timreview/1170
Citation: Hoppe, M. 2019. Choosing an Outlet for Action Research: Publication Patterns in Innovation Journals. Technology Innovation Management Review, 9(4): 66-77. http://doi.org/10.22215/timreview/1234

Keywords: action research, participatory action research, participative, innovation, journals, bibliography, case study 


\section{TIm Technology Innovation Management Review}

\section{Academic Affiliations and Funding Acknowledgements}
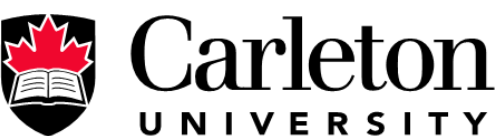

U N I V E R S I T Y

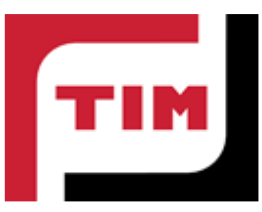

Technology Innovation Management (TIM; timprogram.ca) is an international master's level program at Carleton University in Ottawa, Canada. It leads to a Master of Applied Science (M.A.Sc.) degree, a Master of Engineering (M.Eng.) degree, or a Master of Entrepreneurship (M.Ent.) degree. The objective of this program is to train aspiring entrepreneurs on creating wealth at the early stages of company or opportunity lifecycles.

- The TIM Review is published in association with and receives partial funding from the TIM program. 